\title{
Resenha
}

\section{Stress e o turbilhão da raiva'}

\author{
Stress and anger eddy
}

Ana Carolina de Queiroz CABRAL ${ }^{2}$

A presente publicação tem como objetivo propor um tratamento cognitivo para a raiva, baseado na abordagem cognitivo-comportamental. Essa obra surgiu a partir das pesquisas que sua autora, Marilda Emmanuel Novaes Lipp, vem desenvolvendo na área do stress, da raiva, da qualidade de vida, e no campo do tratamento não farmacológico da hipertensão, trabalho esse de grande reconhecimento.

A autora brinda o público com um texto inovador que reflete sua vasta experiência na área. Ela tem contribuído sistematicamente para enriquecer o conhecimento sobre o tema tanto no Brasil como nos Estados Unidos. Acadêmica, orientou até o momento 56 dissertações e teses de mestrado e doutorado, escreveu 14 livros sobre o stress e dezenas de artigos sobre o tema, desenvolveu o Inventário de Sintomas de Stress para Adultos e é co-autora da Escala de Stress Infantil e da Escala de Stress para Adolescentes.

A obra é composta por uma breve introdução seguida de oito capítulos, além de referências e indicações bibliográficas selecionadas. No decorrer do livro a autora inseriu testes breves e objetivos que permitem o autoconhecimento do leitor, o que foi, certamente, um de seus objetivos.

Em "Por que nos preocupamos com a raiva?" a autora chama a atenção para os aspectos mais relevantes da raiva e sua influência na saúde física e mental, ressaltando ser um fator de risco para o desenvolvimento de doenças coronarianas, do aparelho digestivo, além da sua associação com quadros de depressão, obesidade, problemas de relacionamentos interpessoais, violência na família, divórcio, perda de emprego e suicídio.

Além de explicar a importância da expressão de raiva para a saúde emocional e orgânica, classifica a expressão de raiva em: raiva para dentro; raiva para fora; raiva acompanhada de cinismo. Tendo por suporte uma farta bibliografia, Lipp apresenta evidências das relações entre as expressões de raiva, stress e pressão arterial. Trata de relações muito presentes no cotidiano das pessoas na pós-modernidade.

No capítulo 2, a autora responde à pergunta de seu título, definindo a raiva como um sentimento decorrente de uma grande frustração, ou de uma oposição, e a diferencia da hostilidade quando explica que essa última pode ser concebida como uma característica de personalidade de avaliação das situações e das pessoas de forma negativa. Segundo ela, a hostilidade possui três componentes: cognitivo, ao realizar as avaliações; afetivo, por tratar-se também de um sentimento; e comportamental.

Levando em consideração a proposta de Spielberger, Lipp reforça o aspecto da raiva como

$\boldsymbol{\nabla} \boldsymbol{\nabla} \boldsymbol{\nabla}$

1 Lipp, M.E.N. (2005). Stress e o turbilhão da raiva. São Paulo: Casa do Psicólogo.

2 Pontifícia Universidade Católica de Campinas, Centro de Ciências da Vida, Programa de Pós-Graduação em Psicologia. Av. John Boyd Dunlop, s/n., Prédio Administrativo, Jardim Ipaussurama, 13060-904, Campinas, SP, Brasil. 
mecanismo de proteção contra a perda de poder real ou imaginário. Em seguida, ela faz um histórico das manifestações de raiva desde os tempos bíblicos, preparando assim o leitor para entrar em contato com alguns dos aspectos positivos da raiva, e posteriormente inserir o mecanismo fisiológico desse sentimento.

Nesse mesmo capítulo os tipos de raiva são expostos após a discussão acerca dos hábitos de vida e sua forte influência no comportamento humano. Lipp explica que os hábitos são fortalecidos através da prática e que a reação raivosa pode se tornar um traço de raiva caso se transforme em uma tendência a reagir com raiva em conseqüência de uma interpretação disfuncional da realidade; ou um temperamento raivoso, caso torne-se uma propensão geral daquele indivíduo a vivenciar a raiva sem uma provocação específica anterior. Ressalta, ainda, as hipóteses cultural, familiar e do meio quanto à expressão de raiva. Por fim, defende a existência de vulnerabilidades psicológicas e físicas à raiva, bem como ao stress.

Em seguida, ela aponta os vários aspectos do desenvolvimento da raiva: evento desencadeador e sua interpretação, stress emocional, reavaliação do evento sob a perspectiva da raiva, e escalonamento da raiva. Assim, à luz dos conceitos da abordagem cognitivo-comportamental, é postulado que são as interpretações não funcionais do evento que levam a conclusões equivocadas e, conseqüentemente, à raiva.

O stress é uma reação adaptativa do organismo para a manutenção do seu equilíbrio com o meio que o cerca, garantindo, assim, a homeostase. Tendo por base a produção científica na área, Lipp lembra que qualquer tensão aguda ou crônica que produza mudança no comportamento físico e no estado emocional do indivíduo, ocorrendo uma resposta de adaptação psicofisiológica, é considerada stress. No capítulo 3 a autora aborda a influência do stress na expressão de raiva, bem como ressalta o mecanismo cognitivo e fisiológico desse fenômeno, suas fases, fontes, e seus desdobramentos, como, por exemplo, o stress ocupacional, as possibilidades de ação, a doença da pressa, o padrão de comportamento tipo A e o stress infantil. No texto a autora reforça a importância da aquisição de repertório para enfrentamento de problemas.

Num capítulo específico, Lipp em "A raiva no 126 trânsito" expõe os riscos que a raiva pode oferecer ao indivíduo, especialmente naqueles com nível de stress elevado. Ela explica que, quando da prevalência de stress elevado e raiva mal administrada, ocorre uma hipersensibilidade diante das situações, o que impulsiona a incidência de reações sem grande avaliação prévia, ou também chamadas as reações impulsivas.

Em "A raiva em crianças", a autora explica que a expressão intensa de raiva em crianças pode, assim como nos adultos, se relacionar a uma sensibilidade genética maior do sistema límbico, ou também pode ser o resultado delas terem sido vítimas diretas ou secundárias de violência doméstica ou abuso sexual. A autora expõe as implicações da raiva mal administrada durante a infância, e faz uma explicação do comportamento agressivo, bastante comum nessa fase da vida. É feita uma explanação dos aspectos positivos da raiva referentes à defesa do indivíduo e sua relevância no universo infantil. Além disso, a autora aponta que a maioria das pessoas cronicamente estressadas apresenta dificuldades em lidar com frustrações, respondendo hostilmente, e que um trabalho terapêutico de controle do stress se faz também necessário.

A autora ressalta que a família pode contribuir para a incidência do stress e da raiva. Tal contribuição pode ser caracterizada como múltipla, visto que abrange as áreas cognitiva, social e biológica, desde a estruturação dos esquemas e crenças, até a configuração biológica. Sabe-se que a reação de stress ou de raiva durante a gestação implica conseqüências significantes para o bebê. A autora destaca que o stress pré-natal não pode ser descartado. Baseada em literatura científica, enuncia que a perturbação emocional da gestante proporciona, como conseqüência das alterações bioquímicas sofridas, a liberação da catecolamina, neuro-hormônio liberado em níveis elevados pelo organismo materno em situação de stress e que provoca no feto um estado de perturbação semelhante ao de sua mãe. Como efeito dessa vivência a probabilidade de o futuro bebê apresentar alterações em seu desenvolvimento é alta, como comprovam os estudos realizados com animais cujas mães foram submetidas a fontes de stress durante a gestação. Assim, no $6^{\circ}$ capítulo, o tema da raiva dentro da família é abordado e são feitas indicações para o controle emocional.

No capítulo 7, são expostos os objetivos do treino cognitivo da raiva: (1) apaziguar a excitabilidade 
orgânica gerada pela ação dos hormônios do stress; (2) reestruturar o pensamento pré-raiva; e (3) levar à tomada de ações responsáveis para substituição de reações com raiva por processos conscientes e racionais para o crescimento emocional. Em seguida, são revistos os conceitos e sugeridas técnicas de apoio para o gerenciamento da raiva no momento em que ela ocorre. Dentre essas técnicas, Lipp expõe: a) técnica da mochila para esquecer e reduzir a raiva, um relaxamento que aborda conflitos que, apesar de terem sido vivenciados no passado, têm influência significativa no presente, como, por exemplo, mágoas e ressentimentos; b) estratégia para reduzir a ansiedade, um procedimento de reestruturação cognitiva focado na ansiedade e seu controle; c) técnica do pinheiro, exercício direcionado para o controle da raiva; d) técnica do time out, ou também chamado de férias mentais, cuja proposta é retirar-se da situação que eliciou raiva; e) técnica da ação responsável, focada na solução do problema estruturada em termos cognitivos e emocionais; $f$ ) parada do pensamento, proposta para interromper o processo disfuncional do pensamento; g) respiração profunda, técnica básica de relaxamento; h) técnica do relaxamento, exercício físico e mental que propicia o autocontrole; e exercício físico, responsável pelo equilíbrio neuro-hormonal que é, conforme mencionado anteriormente, fundamental para o controle do stress.

Para finalizar, no capítulo "Especial para quem quiser saber mais sobre a Terapia Comportamental
Cognitiva (TCC) recomendada no transtorno do stress e da raiva", foram feitos apanhados teóricos que situam o leitor nos termos utilizados por essa abordagem teórica da Psicologia. Primeiramente, a autora introduz a TCC através de um breve histórico, para então lançar mão dos pressupostos teóricos que fundamentam a abordagem. Dentre os pressupostos, mereceram destaque a relevância da interpretação (pensamento) dos eventos, e os procedimentos comportamentais e emocionais utilizados para a mudança dos comportamentos e reações emocionais disfuncionais. Em seguida, faz-se uma comparação entre as teorias cognitivas de Becke de Albert Ellis, que posteriormente recebeu algum detalhamento. $O$ encerramento da obra se dá através da exposição teórica da técnica angular da TCC: a reestruturação cognitiva.

O livro Stress e o Turbilhão da Raiva contribui para uma melhor compreensão dessa reação que tanta preocupação e problemas traz para a sociedade, no geral, e para o próprio individuo especificamente, não só enfocando o ponto de vista da vítima da raiva, mas também o referencial da pessoa que sente raiva com freqüência excessiva e não a sabe entender, controlar ou usar adequadamente.

Recebido em: 2/5/2006

Versão final reapresentada em: 26/7/2006

Aprovado em: 16/8/2006 
